\title{
ARDS+TB Paru Kasus Baru dalam Pengobatan OAT Kat 1 Fase Intensif pada G6P5A0H5 Gravid 27-28 Minggu
}

Anggun Pratissa ${ }^{1}$, Defrin ${ }^{2}$

\begin{abstract}
Abstrak
Tuberkulosis (TB) masih menjadi masalah kesehatan di dunia demikian juga tuberkulosis pada kehamilan. Berdasarkan laporan WHO, Indonesia menempati urutan ketiga terbesar angka kejadian TB di dunia setelah Cina dan India. Tuberkulosis pada kehamilan mempunyai gejala klinis yang serupa dengan tuberkulosis pada wanita tidak hamil. Diagnosis mungkin ditegakkan terlambat karena gejala awal yang tidak khas.. Penanganan yang tidak benar pada penderita TB akan menimbulkan berbagai macam komplikasi, salah satunya adalah sindrom gagal nafas dewasa (Adult Respiratory Distress Sindrome/ARDS). ARDS dapat menyebabkan 70\% angka kematian pada penderita TB. Berikut ini dilaporkan kasus seorang pasien wanita dengan usia 38 tahun dengan diagnosis : ARDS + TB Paru kasus baru dalam pengobatan OAT Kat 1 fase intensif pada G6P5A0H5 gravid 27-28 minggu. Tujuan penelitian ini adalah agar diagnosis TB dalam kehamilan dapat ditegakkan secara akurat, sehingga dapat diterapi secara tepat dan tidak menyebabkan resiko yang cukup besar bagi ibu dan janin.
\end{abstract}

Kata kunci: TB, TB pada kehamilan, Gagal nafas, ARDS.

\section{Abstract}

Tuberculosis (TB) is still a health problem in the world as well as tuberculosis in pregnancy. Based on WHO reports, Indonesia ranks third largest TB incidence in the world after China and India. Tuberculosis in pregnancy has clinical symptoms similar to tuberculosis in nonpregnant women. Diagnosis may be late because the initial symptoms are not typical. Improper handling of TB patients will cause various complications, one of which is the Adult Respiratory Distress Syndrome (ARDS). ARDS can cause 70\% mortality in TB patients. The following is the case of a 38-year-old female patient with a diagnosis: ARDS + new case of Pulmonary TB in the treatment of OAT Category 1 intensive phase on G6P5A0H5 gravid 27-28 weeks. The objective of this study was to make a proper diagnose of TB, so we can give proper treatment and also can minimize risk for mother and baby.

Keywords: Tuberculosis, Tuberculosis in pregnancy, respiratory failure, ARDS

Affiliasi penulis : 1 PPDS Bagian Obstetri dan Ginekologi, Fakultas Kedokteran Universitas Andalas, 2 Bagian Obstetri dan Ginekologi, Fakultas Kedokteran Universitas Andalas

Korespondensi : Anggun Pratissa [anggunpratissa@gmail.com] Telp: [082284561989]

\section{PENDAHULUAN}

Tuberkulosis (TB) masih menjadi masalah kesehatan di dunia demikian juga tuberkulosis pada kehamilan. Berdasarkan laporan WHO, Indonesia menempati urutan ketiga terbesar angka kejadian TB di dunia setelah Cina dan India. Di Indonesia, kasus baru tuberkulosis hampir separuhnya adalah wanita, dan menyerang sebagian wanita usia produktif. Kirakira $1-3 \%$ dari semua wanita hamil menderita tuberkulosis. ${ }^{1}$

Tuberkulosis pada kehamilan mempunyai gejala klinis yang serupa dengan tuberkulosis pada wanita tidak hamil. Diagnosis mungkin ditegakkan terlambat karena gejala awal yang tidak khas. Tuberkulosis tidak mempengaruhi kehamilan dan kehamilan tidak mempengaruhi manifestasi klinis dan progesivitas penyakit bila diterapi dengan regimen obat anti tuberkulosis yang tepat dan adekuat. ${ }^{1}$

Pada kehamilan terdapat perubahanperubahan pada sistem humoral, imunologis, peredaran darah, sistem pernapasan, seperti terdesaknya diafragma ke atas sehingga paru-paru terdorong ke atas oleh uterus yang gravid menyebabkan volume residu nafas berkurang. Saat hamil pemakaian oksigen akan bertambah kira-kira $25 \%$ dibandingkan di luar kehamilan, apabia penyakit TB berat atau prosesnya luas dapat menyebabkan hipoksia sehingga hasil konsepsi juga ikut menderita, dapat terjadi partus prematurus atau kematian janin. 2,3

Diagnosis TB dalam kehamilan sangat penting artinya baik bagi ibu hamil maupun bagi janin yang di kandungnya, karena tanpa penanganan yang tepat penyakit ini dapat menyebabkan resiko yang cukup besar bagi keduanya.

Penanganan yang tidak benar pada penderita TB akan menimbulkan berbagai macam komplikasi, salah satunya adalah sindrom gagal nafas dewasa (Adult Respiratory Distress Sindrome/ARDS). ARDS dapat menyebabkan $70 \%$ angka kematian pada penderita TB. Apabila penderita dapat bertahan, maka perbaikan fungsi paru akan membutuhkan minimal waktu 3 bulan. $3,4,5$

\section{LAPORAN KASUS}

Seorang pasien wanita umur 38 tahun, multigrande gravida, dikonsulkan dari bagian paru ke IGD KB RSUP dr.M. Djamil Padang tanggal 19 Juni 
2018 pukul 20.00 WIB kiriman dari RSUD pariaman dalam keadaan sesak yang semakin meningkat sejak 2 hari sebelumnya. Pasien mempunyai riwayat batuk dan sesak sejak 4 bulan sebelumnya yang disertai demam yang hilang timbul, keringat malam dan penurunan berat badan hingga $25 \mathrm{~kg}$ dalam 4 bulan, sehingga pasien dicurigai menderita TB Paru. Saat ini pasien juga sedang dalam keadaaan hamil 27-28 minggu berdasarkan hasil pemeriksaan USG (gambar 1)

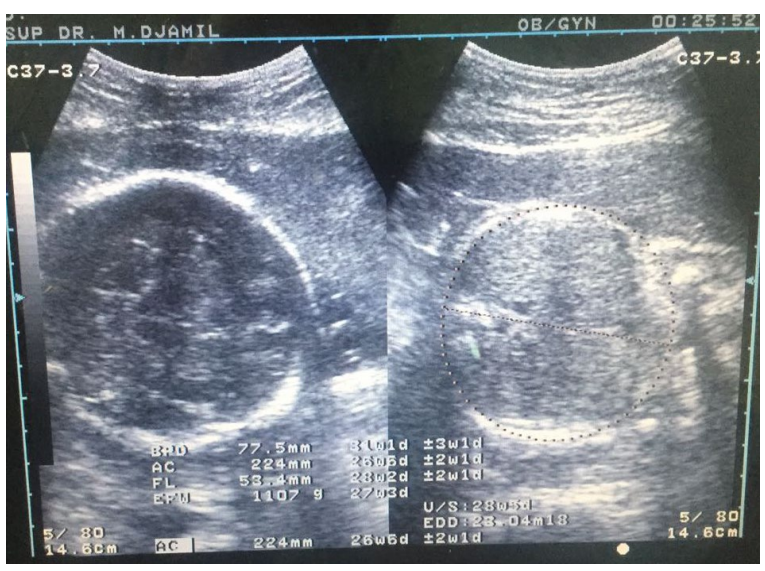

Gambar 1 Hasil USG

Pasien dirawat bersama dibagian Paru diberi tatalaksana terapi oksigen, terapi pematangan paru, dan anti piretik. Kepada Pasien dan suami di beri informed consent tentang perjalanan penyakit dan kemungkinan kematian janin intra uterin. Dari hasil pemeriksaan Laboratorium didapatkan pasien mengalami Anemia sedang, elektrolit imbalance, gangguan fungsi hati dan mengalami Asidosis metabolik dengan hipoksia berat.

Diagnosa TB Paru ditegakkan berdasarkan Hasil TCM: MTB Detected medium dan Rifampicin resistance not detected, serta dari Ro thorax didapatkan kesan TB Paru dan Kardiomegali. Kemudian pasien mulai diberikan terapi OAT kategori I fase intensif.

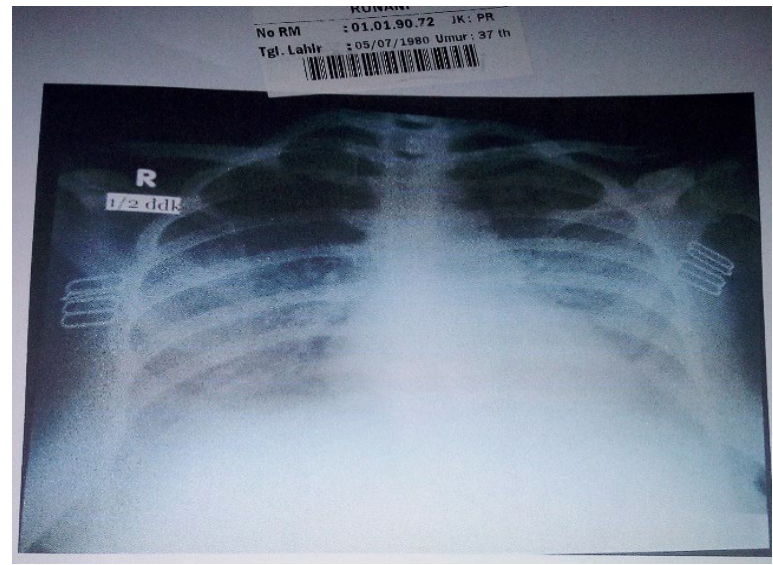

Gambar 2. Rontgen Thorak

Memasuki hari kedua rawatan (21/6/2018) pasien bertambah sesak dan ditegakkan diagnosa ARDS berdasarkan gejala klinis dan pemeriksaan Analisa Gas Darah. Pada hari ke empat rawatan
(23/6/2018) pasien mengalami perburukan dan penurunan kesadaran. Pada pukul 21.30 keluarga memberi tahu pasien dalam keadaan tidak sadarkan diri, dan setelah diperiksa dinyatakan pasien meninggal dunia didepan keluarga dan paramedis.

\section{DISKUSI}

Tuberkulosis merupakan penyakit yang disebabkan oleh mikroorganisme Mycobacterium tuberkolusis yang merupakan salah satu penyakit saluran pernafasan bagian bawah karena sebagian besar basil tuberkolusis masuk ke dalam jaringan paru melalui airbone infection. ${ }^{6}$ Pada pasien ini dicurigai menderita TB paru berdasarkan anamnesis yang didapatkan rwayat batuk dan sesak sejak 4 bulan yang lalu yabg bertambah berat sejak 2 hari ini, riwayat demam yang hilang timbul sejak 3 bulan, keringat pada malam hari dan penurunan berat badan hingga $25 \mathrm{~kg}$ dalam 4 bulan. Selama perawatan, pasien dilakukan pemeriksaan untuk menegakkan TB Paru dan didapatkan dari hasil TCM: MTB Detected medium dan Rifampicin resistance not detected, serta dari Ro thorax didapatkan kesan TB Paru dan Kardiomegali.

Pada pasien ini diberikan tatalaksana OAT dan terapi oksigen, namun terapi yang diberikan belum adekuat dikarenakan berdasarkan literatur yang ada maka tatalaksana standar pada pasien dengan ARDS adalah sebagai berikut: pemberian terapi oksigen, penatalaksanaan obstruksi jalan nafas, pengobatan infeksi pulmonal, pengaturan jumlah sekret, dan membatasi terjadinya edema pulmonal. Selain itu, beban otot pernafasan harus dikurangi dengan penggunaan ventilasi mekanik. Koreksi abnormalitas juga harus dilakukan terhadap abnormalitas yang menyebabkan kelemahan otot pernafasan, seperti misalnya hipofosfatemia dan malnutrisi .3,4

ARDS adalah kasus kegawatdaruratan medis sehingga penanganannya harus cepat dan tepat. Pembukaan jalan napas dilakukan dengan pemasangan endotrakeal tube (ETT). Pemberian oksigen dengan sungkup hidung atau wajah dilakukan untuk menghilangkan hipoksi. Tujuannya adalah untuk meningkatkan perfusi ke seluruh jaringan, terapi berhasil jika $\mathrm{PaO}_{2}>60 \mathrm{mmHg}$ atau saturasi oksigen arterial $\left(\mathrm{SaO}_{2}\right)>90 \%$. Pemberian oksigen akan memberikan tekanan positif yang akan membantu usaha napas dan meringankan kerja otot pernapasan. Efek samping pemberian oksigen adalah toksisitas oksigen dan narkosis karbondioksida. Toksisitas oksigen tidak terjadi bila $\mathrm{FiO}_{2}$ (fraksi konsentasi oksigen di dalam udara inspirasi) $<0,6$. Narkosis karbondioksida terjadi bila pasien yang mengalami hiperkapni diberi oksigen yang menyebabkan vasokonstriksi arteri pulmonal dan peningkatan dead space. $\mathrm{PaCO}_{2}$ akan meningkat dengan cepat kemudian terjadi asidosis respiratori, somnolen dan koma. ${ }^{7,8}$ 
Pasien yang sangat sulit bernapas yang disertai dengan hiperkapni dan asidosis respiratorik memerlukan ventilator untuk membantu pernapasan. Tujuannya adalah meningkatkan $\mathrm{PaO}_{2}$ dan menurunkan $\mathrm{PaCO}_{2}$. Tube plastik yang dimasukkan melalui hidung atau wajah dan menuju trakea dihubungkan dengan mesin yang akan mengalirkan udara ke paru-paru. Pasien dengan ventilator dapat mengalami agitasi maka perlu diberikan obat penenang seperti lorazepam, midazolam, morfin atau fentanil. 8,9

Indikasi pemasangan ventilasi mekanik adalah pertukaran gas yang memburuk. Pemasangan ventilasi mekanik penting dilakukan pada pasien pneumonia atau TB yang mengalami hipoksemia dan hiperkarbia berat. Karena pengobatan dengan antibiotika untuk mengatasi infeksi paru memerlukan waktu untuk memperbaiki keadaan pertukaran gasnya..$^{3,6}$

Hipoksemia sangat mengganggu fungsi organ sehingga tujuan utama terapi pada gagal napas adalah mencegah atau memperbaiki hipoksemi jaringan. Hiperkapni tanpa hipoksemi masih dapat ditoleransi karena tidak mengganggu perfusi jaringan kecuali ada asidosis berat. Pasien dengan ARDS harus dirawat di ruang intensif atau ruang respiratory care. Penanganan penyakit yang mendasari gagal napas perlu dilakukan dengan tepat agar prognosis baik. $^{8}$

Kondisi pada pasien ini adalah ARDS yang berkelanjutan yang menyebabkan adanya hipoksemia berat yang menimbulkan asidosis dan gangguan perfusi organ lainnya. ARDS yang berkembang perlahan makan akan dapat menimbulkan terjadinya hiperternsi pulmonal yang akan menyebabkan semakin meningkatkanya progresivitas ARDS sehingga menyebabkan kegagalan multi organ dan akhirnya mengakibatkan kematian.

\section{SIMPULAN}

Infeksi TB pada kehamilan mungkin memilki gambaran yang menyulitkan untuk didiagnosis, terutama karena gejala awalnya yang kadang nonspesifik. Selain ini, gambaran TB pada wanita hamil serupa dengan wanita tidak hamil, dimana TB pulmonal merupakan manifestasi klinik yang paling sering ditemui. Langkah yang paling penting untuk membuat diagnosis dalam kehamilan adalah identifikasi faktor resiko infeksi TB dan pemeriksaan khusus mengenai gejala untuk menduga adanya infeksi. Skrining rutin TB dalam kehamilan tidak standar dilakukan di beberapa daerah dan hal inilah yang merupakan salah satu faktor yang dianggap dapat menyebabkan diagnosis terlambat dan pada akhirnya berperan dalam kematian ibu.

\section{DAFTAR PUSTAKA}

1. Global Tuberculosis Report. World Health Organization. 2017; 23:5-6
2. Khilnani, G.C. Tuberculosis and Pregnancy. Department of Medicine. The Indian Journal of Chest Dis Allied Sci. 2004; 46(2):105-11.

3. Ghosh K, Chowdhury J, Ghosh K. Tuberculosis and female reproductive health.Journal of Postgraduate Medicine. 2011; 57(4):307-14.

4. JY. Kim, YB. Park, YS Kim. Miliary tuberculosis and acute respiratory distress syndrome. INT J TUBERC LUNG DIS. 2013; 7(4):359-64

5. Kecia, Apuzzio J.Tuberculosis in Pregnancy: Infectious Diseases in Obstetrics and Gynecology (C). Wiley-Liss, Inc.Department of Obstetrics and Gynecology, UMDNJ-New Jersey Medical School, Nearb, NJ. 2006; 4:92-6.

6. Kothari A, Girling J. Tuberculosis and pregnancy: result of a study in a high prevalence area in London. Eur J Obstet Gynecol. 2016; 126:48-55.

7. API TB Consensus Guidelines. Management of pulmonary tuberculosis, extra pulmonary tuberculosis and tuberculosis in special situations. J Assoc Physician India. 2006; 54:219-34.

8. Monchi M, Bellenfant F, Cariou A, Joly L, Thebert D, Laurent I, Dhainaut J, Brunet F. A. Multivariate analysis-early predictive factors of survival in the acute respiratory distress syndrome. Am J Respir Crit Care Med. 2008;158:1076-81.

9. Bhadade RR, de Saouza RA, Harde MJ, Khot A. Clinical characteristic and outcome of patients with acute lung injury and acute respiratory distress syndrome in. Topiwala National Medical College Journals. 2015; 57:286-90.

10. Christiane S, Pelosi P, Rocco P. Pulmonary and extrapulmonary acute respiratory distress syndrome: are they different? Rev Bras Ter Intensiva. 2014; 20:178-83. 